\title{
Erratum to: Quality improvement of recycled fine aggregate using steel ball with the help of acid treatment
}

\author{
Ha-Seog Kim ${ }^{1} \cdot$ Jin-Man Kim$^{1} \cdot$ Byoungil Kim $^{2}$
}

Published online: 19 September 2017

(c) Springer Japan KK 2017

\section{Erratum to: J Mater Cycles Waste Manag DOI 10.1007/s10163-017-0639-8}

Unfortunately, the author's affiliations have been incorrectly published in the original publication of the article. The correct affiliations are provided in this erratum.

The online version of the original article can be found under doi:10.1007/s10163-017-0639-8.

\section{Byoungil Kim}

bikim@seoultech.ac.kr

1 Department of Architectural Engineering, Kongju National University, 275 Cheonan-daero, Cheonan, Chungcheongnam-do 330-717, Korea

2 Department of Architectural Engineering, School of Architecture, Seoul National University of Science and Technology, Gongneung-Ro, Nowon-Gu, Seoul 01811, Korea 